\title{
Pediatric Anesthesia: An Emerging Specialty in India
}

\author{
Preethy J Mathew ${ }^{1}$, Anoop Sharma ${ }^{2}$ \\ Keywords: Emerging speciality, Indian healthcare, Pediatric anesthesia. \\ Journal of Postgraduate Medicine, Education and Research (2022): 10.5005/jp-journals-10028-1551
}

The practice of anesthesia has been pivotal over the last 100 years to enable surgical treatment for a myriad of disease conditions. In the recent decades, technological strides and advances in both surgery and anesthesia have enhanced patient safety with significant reduction in perioperative death. ${ }^{1}$ The skill-set required to perform surgeries in neonates, infants, and children are distinct and more demanding than that required to manage older counterparts as implicit in the adage "Children are not small adults." Similarly, the competence essential to anesthetize them is equally challenging involving a mix of aptitude, attitude, and refined high-precision skills to manage their perioperative period.

The understanding of the unique demands to cater to the perioperative needs of this younger cohort of population led to the growth of super-specialties such as pediatric surgery and pediatric anesthesia during the 1940s in the Western world. The pathbreaking progress by pioneers such as William Ladd (surgeon), Charles Robson (anesthesiologist), and Philip Ayre (anesthesiologist) ${ }^{2,3}$ spurred the recognition of pediatric surgery and pediatric anesthesia as separate entities. Formal training and teaching programs in the subspecialty of pediatric anesthesia were first introduced in Montreal Children's Hospital in 1940 by Morton Digby Leigh and other leading children's hospitals around the world soon followed suit. ${ }^{4}$ Incidentally, the APGAR score which is so widely used globally to assess newly born infants was developed in 1953 by Virginia Apgar, who was a pediatric anesthesiologist. ${ }^{2}$

On the national front, pediatric surgery evolved in the 1960s triggered by the inception of the first independent pediatric surgery division in our country under Prof IC Pathak at PGIMER, Chandigarh in 1968. Soon, postdoctoral (MCh) course in pediatric surgery was started in $1969^{5}$ to train surgical residents, who went on to become the current national leaders of the specialty in this country. The evolution of pediatric anesthesia as a subspecialty has been slower in comparison. However, PGIMER initiated a Fellowship program in 2016 becoming the country's first institution to do so. Very soon, the DM (Pediatric Anesthesia and Intensive Care) course was started in 2019, with the hope to train manpower for highly advanced and specialized skill-set and thus contribute to enhancing perioperative quality and outcomes in India.

Although pediatric and neonatal anesthetic techniques have advanced tremendously in recent years, the large majority of such procedures in India are currently performed by practitioners who manage both adults and children in their practice. This situation is due to the paucity of dedicated programs to train specialists in pediatric anesthesia and is the need of the hour. Pediatric

\footnotetext{
1,2Department of Anaesthesiology and Intensive Care, Postgraduate Institute of Medical Education and Research, Chandigarh, India

Corresponding Author: Preethy J Mathew, Department of Anaesthesiology and Intensive Care, Postgraduate Institute of Medical Education and Research, Chandigarh, India, Phone: +91 9417800203, e-mail: tjpreethy@gmail.com

How to cite this article: Mathew PJ, Sharma A. Pediatric Anesthesia: An Emerging Specialty in India. J Postgrad Med Edu Res 2022;56(1):51-52.

Source of support: Nil

Conflict of interest: None
}

anesthesiologists are more experienced and more adept in handling younger children compared to a general anesthesiologist. Quicker decision making, faster placement of peripheral intravenous access and airway, and finer ease in positioning anesthetized children are some of the aspects performed better by pediatric anesthesiologists when compared to practitioners who anesthetize children occasionally. ${ }^{5}$ These qualities eventually aid an efficient use of operating room time.

In the subset of children who are neonates, performing surgery and providing anesthesia are even more demanding, and require the highest level of expertise owing to the negligible margin of error possible in these vulnerable patients. The mortality amongst surgical neonates ranges from $30-35 \%{ }^{6}$ and the risk is often compounded by prematurity, low birth weight, and life-threatening congenital anomalies. The role of appropriate training is paramount to build individual capability and institutional capacity, to manage such high risk patients in order to improve the neonatal perioperative outcomes in the Indian healthcare setting.

The exposure of postgraduate trainees to pediatric anesthesia is limited due to lack of infrastructure and experienced pediatric anesthesiologists in the large majority of teaching institutions. ${ }^{7}$ In addition, the situation of shortage of anesthesiologists in our country sometimes leads to scenarios where conscious sedation services are managed by pediatric specialists. For example, in our institution, sedation for MRI, nuclear medicine, and CT scan procedures are often administered by pediatric trainees. It is time to train and expand the pediatric anesthesia services to relieve colleagues from pediatrics of the burden of conscious sedation, at least in our institute.

There are various major issues that challenge pediatric anesthesiologists worldwide such as implications of anesthetic exposure on the immature brain, establishing a standard of

\footnotetext{
(c) The Author(s). 2022 Open Access This article is distributed under the terms of the Creative Commons Attribution 4.0 International License (https://creativecommons. org/licenses/by-nc/4.0/), which permits unrestricted use, distribution, and non-commercial reproduction in any medium, provided you give appropriate credit to the original author(s) and the source, provide a link to the Creative Commons license, and indicate if changes were made. The Creative Commons Public Domain Dedication waiver (http://creativecommons.org/publicdomain/zero/1.0/) applies to the data made available in this article, unless otherwise stated.
} 
care in children and neonates with difficult airways, improving perioperative outcomes in neonates and children, etc. Various international collaborations have evolved in the last decade to address these issues globally in a collective framework. Pediatric Difficult Intubation Registry, Pediatric Anesthesia COVID Collaboration, Pediatric Regional Anesthesia Network, and Wake Up Safe are a few examples of multi-institutional collaboration to share data and resources regarding certain specific clinical problems. ${ }^{1}$ The work of some recent multicentric collaborations and studies have been path breaking and practice changing in addition to generating important epidemiological data relevant to perioperative outcomes. ${ }^{8}$ For example, the Pediatric Anesthesia Neurodevelopment Assessment study revealed that a single anesthetic exposure in early infancy does not increase the risk of cognitive dysfunction in children. ${ }^{9}$ Similarly, the Anaesthesia Practice In Children Observational Trial of 30,874 children in Europe reported a $5.2 \%$ incidence of perioperative critical events and mortality of 10:10,000. ${ }^{10}$

It would be beneficial for Indian institutions to collaborate selectively with some of the above mentioned international collaborations to generate national and local data as well as propel pediatric anesthesia research to the forefront. Our department has initiated a few steps in this direction to collaborate with Wake Up Safe Foundation and Indian Association of Paediatric Anaesthesiologists.

In conclusion, pediatric anesthesia as a subspecialty is in its initial years at present in India, yet promises trainees an opportunity to learn new skills and explore new areas of multi-institutional collaborative research.

\section{References}

1. Walters CB, Kynes JM, Reddy SK, et al. Pediatric anesthesia specialty societies and multi-institutional collaborations. Children (Basel) 2020;7(11):233. DOI: 10.3390/children7110233

2. Mai $\mathrm{CL}$, Coté $\mathrm{CJ}$. A history of pediatric anesthesia: a tale of pioneers and equipment. Paediatr Anaesth 2012;22(6):511-520. DOI: $10.1111 / \mathrm{j} .1460-9592.2012 .03828 . x$

3. Ayre P. Anæsthesia for hare-lip and cleft palate operations in babies. Br J Surg 1937;25(97):131-132. DOI: 10.1002/bjs.1800259716

4. Leigh MD, Belton MK, Lewis GB. Pediatric anesthesia. Anesth Analg 1956;35(1):1-17. DOI: 10.1213/00000539-195601000-00001

5. Dewyer NA, Kram YA, Long S, et al. Impact of a pediatric anesthesiologist on operating room efficiency during pediatric tonsillectomies and adenotonsillectomies. Ear Nose Throat J 2017;96(6):E24-E238. DOI: 10.1177/014556131709600605

6. Gangopadhyay AN, Upadhyaya VD, Sharma SP. Neonatal surgery: a ten year audit from a university hospital. Indian J Pediatr 2008;75(10):1025-1030. DOI: 10.1007/s12098-008-0205-4

7. Dave N, Verghese E, Jacob R. Challenges and opportunities facing pediatric anesthesia providers in Low- and Middle-Income Countries (LMICs), India. Paediatr Anaesth 2021;31(1):47-52. DOI: 10.1111/ pan. 14053

8. de Graaff JC, Engelhardt T. How big data shape paediatric anaesthesia. Br J Anaesth 2017;119(3):448-451. DOI: 10.1093/bja/aex158

9. Davidson AJ, Disma N, de Graaff JC, et al. Neurodevelopmental outcome at two years of age after general and awake-regional anaesthesia in infancy: a randomised controlled trial Lancet 2016;387(10015):239-250. DOI: 10.1016/S0140-6736(15)00608-X

10. Habre W, Disma N, Virag K, et al. Incidence of severe critical events in paediatric anaesthesia (APRICOT): a prospective multicentre observational study in 261 hospitals in Europe. Lancet Respir Med 2017;5(5):412-425. DOI: 10.1016/S2213-2600(17)30116-9 